\title{
Contribuições \\ piagetianas ao ensino de Jornalismo
}

\section{Rodrigo Pelegrini Ratier}

Professor do curso de jornalismo da Faculdade Cásper Líbero (SP). Doutor em Educação pela Universidade de São Paulo (FE-USP). Pesquisador do Grupo de Pesquisa Práticas de Socialização Contemporâneas (GPS-FEUSP).

E-mail: rpratier@casperlibero.edu.br

Resumo: $O$ artigo pretende apresentar contribuições do pensamento de Jean Piaget ao ensino de jornalismo. Enfoca-se a natureza ativa do educando na construção de conhecimento, conforme preconizado pelas Diretrizes Curriculares Nacionais (DCNs) para o curso de Jornalismo (MEC/ CNE, 2013), bem como a importância do conflito cognitivo, o valor do erro e do conhecimento sobre como se constrói a aprendizagem. Embora Piaget não tenha concebido uma metodologia pedagógica, adaptações, apropriações reflexões e novas teorizações acerca de preceitos de sua epistemologia genética podem oferecer abordagens para processos de ensino e de aprendizagem construtivistas. Neste ensaio, elabora-se um diálogo entre as DCNs e os modelos didáticos de inspiração piagetiana, propostos por Gruber e Vonèche (1977) e atualizados por Macedo (2012).

Palavras-Chave: construtivismo; Piaget; ensino de jornalismo; epistemologia genética; aprendizagem ativa.
Abstract: The article aims to present contributions of Jean Piaget's thought to the teaching of journalism. It focuses on the active nature of the student in the construction of knowledge, as recommended by the National Curriculum Guidelines for the Journalism Course (MEC / CNE, 2013), and the importance of cognitive conflict, the value of error and the knowledge about how learning is constructed. Although Piaget did not conceive a pedagogical methodology, adaptations, appropriations, reflections and new theorizations about the precepts of his genetic epistemology can offer approaches to constructivist teaching and learning processes. In this paper, a dialogue is elaborated between the DCNs and the didactic models of Piagetian inspiration proposed by Gruber and Vonèche (1977) and updated by Macedo (2012).

Keywords: constructivism; Piaget; journalism teaching; genetic epistemology; active learning. 
1. ABRAMO, Perseu. Jornalismo: profissão específica ou atividade geral? Folha de S.Paulo, São Paulo, 2 out. 1987. Disponível em: https:// www.lainsignia.org/2001/ junio/cul_054.htm. Acesso em: 1 ago. 2020.

2. MEDITSCH, Eduardo. Novas e velhas tendências: os dilemas do ensino de jornalismo na sociedade da informação. Revista Brasileira de Ensino de Jornalismo, Brasília, DF, v. 1, n. 1 , p. 179-201, 2007.

3. Pela ordem cronológica em que aparecem em Gadotti (1997): Lao-Tsé, Talmude, Sócrates, Platão Aristóteles, Cícero, Quintiliano, Santo Agostinho, São Tomás de Aquino, Montaigne, Lutero, Os Jesuítas Comênio, Locke Rousseau Pestalozzi, Herbart, Revolução Francesa, Spencer Durkheim, Whitehead Marx, Lênin Makarenko, Gramsci, Dewey, Montessori, Claparède, Piaget Buber Korczak Gusdorf Pantillon, Freinet, Rogers, Lobrot, Bourdieu, Passeron, Baudelot, Establet, Giroux Cabral, Nyerere, Faundez, Francisco Gutiérrez, Rosa Maria Torres, Maria Tereza Nidel coff Emilia Ferreiro Juan Carlos Tedesco, Fernando de Azevedo, Lourenço Filho, Anísio Teixeira Roque Spencer Maciel de Barros, Paschoal Lemme Alvaro Vieira Pinto, Paulo Freire Rubem Alves, Maurício Tragtenberg, Dermeva Saviani, Unesco, Furter, Schwartz, Skinner, McLuhan, Illich, Suchodolski, Snyders.

4. GADOTTI, Moacir. História das ideias pedagógicas. 4. ed. São Paulo: Atica, 1996.

5. BRASIL. Ministério da Educacão. Conselho Nacional deEducação. Resolução ${ }^{\circ} 1$, de 27 de setembro de 2013. Institui as Diretrizes Curriculares Nacionais para o curso de graduação em Jornalismo, bacharelado e dá outras providências. Diário Oficial da União: seção 1, Brasília, DF, p. 26 27 set. 2013. Disponível em http:/portal mec govbr/in dexphp?option=com docman\&view= downloaḋalias $=14242-$ rces001-13\&category slug=setembro 2013-pdf\&ltemid=30192 Acesso em: 1 ago. 2020.

6. BRASIL, op. cit., grifo nos so.

\section{INTRODUÇÃO}

"Jornalismo: profissão específica ou atividade geral?”, pergunta Abramo", em texto clássico do campo. O já então experiente sociólogo, jornalista e professor defende a tese de uma atividade geral que, com a complexificação do mundo, foi se transformando em profissão específica. São peculiares, defende o autor, as operações que envolvem o trato com a informação: planejamento, obtenção de informação, organização, estruturação, hierarquização, explicação, análise, interpretação, apresentação e difusão. Merecem, portanto, formação igualmente específica, não redutível a outras formações, com componentes que atendam às necessidades sociais esperadas para a profissão: projeto pedagógico, eixos de formação, conteúdos curriculares, habilidades e competências a serem desenvolvidas etc.

Em outras palavras, a especificidade profissional exige que se pense o ensino do jornalismo enquanto atividade educativa. Em outro texto conhecido sobre os dilemas do ensino de jornalismo, Meditsch ${ }^{2}$ cita o relatório The winds of change, Challenges confronting journalism education para reivindicar o jornalismo como atividade intelectual e os jornalistas como educadores, mencionando Elias Machado para pontuar a necessidade de se construir teorias e metodologias próprias.

Há extensa produção quanto às metodologias do ensino de jornalismo. Observa-se, porém, pouca interlocução com os autores clássicos do campo da educação. A título de ilustração, fizemos uma busca por palavras-chave no acervo da Revista Brasileira do Ensino de Jornalismo (Rebej). Realizamos pesquisas sobre os 67 autores/instituições/obras e marcos fundamentais ${ }^{3}$ que compõem os capítulos e seções do livro História das ideias pedagógicas ${ }^{4}$, tido como obra de referência nos cursos de História da Educação. Apenas dois deles retornaram com resultados: Paulo Freire (sete artigos) e Unesco (dois artigos). Podemos, assim, avançar nessa interlocução.

Quais diálogos estabelecer? As Diretrizes Curriculares Nacionais para o Ensino de Jornalismo ${ }^{5}$, principal referência para a organização dos cursos de formação inicial, são econômicas quanto a referências metodológicas. Relacionada ao contexto de ensino e de aprendizagem, a palavra "metodologia" aparece apenas duas vezes. $\mathrm{O}$ art. 15 afirma que os planos das disciplinas, fornecidos aos educandos antes do início do período letivo, devem conter, entre suas informações, dados sobre a metodologia das aulas. Porém, é no art. 2, que dispõe sobre a estrutura do curso de bacharelado, que encontramos indicações mais precisas sobre a natureza da metodologia a ser favorecida na graduação:

Art. $2^{\circ}$ A estrutura do curso de bacharelado em Jornalismo deve: [...] II - utilizar metodologias que privilegiem a participação ativa do educando na construção do conhecimento e a integração entre os conteúdos, além de estimular a interação entre o ensino, a pesquisa e a extensão, propiciando suas articulações com diferentes segmentos da sociedade ${ }^{6}$.

Nesse sentido, a perspectiva educacional advinda do pensamento de Jean Piaget aparece como referência relevante para as práticas em sala de aula. Enquanto pesquisador do desenvolvimento humano e dos processos de aprendizagem, o suíço 
oferece inspirações para um ensino pautado no protagonismo do educando, tendo como eixo fundante a ação do aprendiz como construtor do próprio conhecimento.

O presente ensaio não propõe um exame exaustivo. Dadas a extensão da obra de Piaget - cerca de 50 livros e centenas de artigos nas contas de Gruber e Vonèche ${ }^{7}$ e a diversidade de seus objetos de pesquisa - da zoogeografia à matemática, passando pelo desenvolvimento infantil e o papel da afetividade na aprendizagem -, o mais prudente é apontar conexões possíveis entre suas teorias do processo de desenvolvimento intelectual e de suas concepções sobre educação com o ensino de jornalismo. É o que pretendemos fazer nas seções que compõem este artigo.

A seção dois se dedica a situar a posição dos estudos de Piaget na história das ideias pedagógicas. Apresenta-se sumariamente a perspectiva renovadora a que se dedica. A seção três aborda os mecanismos básicos por meio dos quais se dá, na visão piagetiana, o aprendizado intelectual. A seção quatro se detém a explorar as concepções de educação do autor, enquanto as seções cinco e seis, mais aplicadas, trazem, respectivamente, uma proposta de sistematização da concepção piagetiana para os processos de ensino e aprendizagem escolares e apontamentos preliminares quanto ao diálogo com o ensino de jornalismo.

\section{PIAGET E A APRENDIZAGEM ATIVA}

Em sua História das ideias pedagógicas, Gadotti classifica a Escola Nova como "o mais vigoroso movimento de renovação da educação depois da criação da escola burguesa" ${ }^{8}$. A denominação abriga não um grupo coeso, mas propostas de diferentes autores do início do século XX. O nó de amarração do "movimento" é a ideia de fundamentar o ato pedagógico na ação do educando - segundo Gadotti", perspectiva que vinha se consolidando desde o século XV, com a "escola alegre" de Vitorino de Feltre (1378-1446).

Adolphe Ferrière (1879-1960) é tido como o fundador da moderna Escola Nova. Criador do termo e redator de uma espécie de carta de princípios, Ferrière fundou um birô internacional das Escolas Novas, articulação internacional de instituições pautadas em colocar a criança como centro das práticas educativas. Escrevendo a partir dos Estados Unidos, John Dewey (1859-1952) defendeu o learning by doing - o ensino a partir da ação diante de um problema -, compartimentando a atividade intelectual nos cinco estágios do ato de pensar: uma necessidade sentida diante da dificuldade/desafio, a análise da dificuldade, as alternativas de solução, a experimentação de opções e a ação com a solução proposta.

Com as novas concepções, renovavam-se os métodos de ensino. William Heard Kilpatrick (1871-1965) defendeu o método dos projetos centrado em atividades práticas. Ovide Decroly (1871-1932) propôs o método dos centros de interesse (família, universo, mundo vegetal, mundo animal) que disparariam a atenção da criança e os processos de observação, associação e expressão. Roger Cousinet (1881-1973) foi defensor do método de trabalho por equipes, enquanto Édouard Claparède (1873-1940) cunhou o termo educação funcional para pontuar que nem toda atividade geraria uma ação,

7. GRUBER, Howard E.; VONĖCHE, J. Jacques. The essential Piaget. London: Routledge: Kegan Paul, 1977. 
8. GADOTTI, Moacir. op.

cit., p. 142.

9. Ibidem.

10. GRUBER, Howard E. VONĖCHE, J. Jacques. op. cit., p. xvi.

11. PIAGET, Jean. Epistemologia genética. São Paulo: Martins Fontes, 2002, p. 8.

12. BARTELMEBS, Roberta Chiesa. Psicogênese e história das ciências: elementos para uma epistemologia construtivista. Revista Ensaio, Belo Horizonte, v. 16, n. 2, p. 147-165, 2014.

13. LOURENÇO, Orlando; MACHADO, Armando. In defense of Piaget's theory: a reply to 10 common criticisms. Psychological Review, [s. l.], v. 103, n. 1, p. 143-164, 1996.

14. Ibidem, p. 150.

15. PIAGET, Jean. op. cit., 2002, p. 9.

16. Ibidem, p. 4.

17. BARTELMEBS, Roberta Chiesa, op. cit. mas apenas as que correspondiam a funções vitais do ser humano. Estas poderiam, efetivamente, ser chamadas de atividades educativas.

Jean Piaget (1896-1980) foi discípulo e colaborador de Claparède. Interessado em entender como ocorre o conhecimento humano e tendo como linha central de pesquisa a psicologia da infância, ele obtém reconhecimento no campo comparável, segundo Gruber e Vonèche ${ }^{10}$, apenas a Freud e Skinner. Em homenagem, no ano de 1969, a Associação Americana de Psicologia declarou que seu trabalho tocava, de maneira empírica, em questões humanas antes tratadas apenas pela filosofia.

Ao buscar as origens infantis do conhecimento humano em diversos campos (lógica, espaço, tempo, linguagem, matemática, moral etc.), Piaget cria a epistemologia genética - a expressão refere-se à investigação da gênese dos conhecimentos -, teoria que se afasta das concepções então dominantes do inatismo (a formulação kantiana de que o conhecimento já se encontra nas estruturas do sujeito, cabendo à educação "extrai-los") e do empirismo (a ideia de que o conhecimento está no meio exterior e é preciso "adquiri-lo" pelo acúmulo de experiências). Para Piaget, o conhecimento é construído pelo sujeito - daí a nomeação de sua epistemologia como construtivista - e "resultaria de interações que se produzem a meio caminho entre sujeito e objeto, e que dependem, portanto, dos dois ao mesmo tempo" ${ }^{11}$.

Com efeito, Bartelmebs ${ }^{12}$ afirma que a estrutura da epistemologia genética é a interação entre sujeito e objeto do conhecimento, perspectiva que enfatiza aspectos biológicos e psicológicos na aprendizagem. Se, de fato, esses eram os enfoques predominantes em parte de sua obra, é preciso assinalar as várias modificações da teoria piagetiana, particularmente aquelas elaboradas a partir de 1970. Para Lourenço e Machado ${ }^{13}$, as críticas à ausência de fatores sócio-históricos na teoria piagetiana vai de encontro a diversas afirmações de Piaget, que defendeu a necessidade de o sujeito do conhecimento se engajar em trocas intelectuais e na cooperação com seus pares e de que aspectos sociais são necessários para o desenvolvimento cognitivo ${ }^{14}$.

Para marcar posição em relação aos empiristas, o autor sustenta que o instrumento de troca inicial na relação sujeito-objeto não é a percepção, mas a ação - "e é, portanto, da ação que convém partir" ${ }^{\text {" }}$. Afirma, ainda, que o desenvolvimento dos conhecimentos é uma construção contínua e se dá "da passagem de um conhecimento menos bom ou mais pobre para um saber mais rico (em compreensão e extensão)" ${ }^{\prime 16}$. Não se trata, porém, de evolução linear ou de substituição de conhecimentos, mas da interação de "novos" conhecimentos com outros de níveis mais elementares, resultando em um processo de construção que, como veremos a seguir, pode assumir variadas formas ${ }^{17}$.

\section{O APRENDIZADO INTELECTUAL SEGUNDO PIAGET}

No campo da educação, o trabalho de Piaget é mais comumente conhecido pelo conceito de estádio. Trata-se das etapas do desenvolvimento da criança, que segundo Piaget ocorrem universalmente e na mesma ordem, representando os quatro principais períodos de desenvolvimento cognitivo: sensório-motor $(0$ a 2 anos, com o conhecimento do mundo baseado nos sentidos e habilidades motoras); 
pensamento pré-operatório (3 a 6 anos, com o mundo entendido pela percepção imediata e individual, contemplando o uso de símbolos, palavras e números para representá-lo); pensamento operatório-concreto (7 a 11 anos, com a aplicação de operações lógicas e o início das verificações mentais); e pensamento operatório-formal (adolescência em diante, caracterizado por abstração, dedução, imaginação, planejamento e especulação).

Segundo Lourenço e Machado ${ }^{18}$, as críticas recorrentes à fixação de idades ao desenvolvimento cognitivo dos sujeitos derivam de um "equívoco generalizado" de interpretação da teoria piagetiana, cujo interesse residiria mais na sequência de etapas do que na idade da aquisição ${ }^{19}$. Na mesma linha, Bartelmebs ${ }^{20}$ pontua que "não há idades pré-determinadas, uma vez que os processos cognitivos são dinâmicos e dependem de mais de um fator para que ocorram" e que os estádios não devem ser entendidos como passagens de um lugar para outro, mas como "condições de possibilidade" até onde o sujeito consegue ir dentro de um mesmo nível de desenvolvimento ${ }^{21}$.

Apesar da notoriedade, Gruber e Vonèche ${ }^{22}$ não atribuem ao conceito de estádio posição central na teoria piagetiana. Muito mais importante, afirmam, são as ideias gerais sobre o desenvolvimento intelectual, que valem para qualquer ponto da vida:

Em qualquer ponto de seu desenvolvimento, pode-se descrever [o intelecto] como um conjunto de estruturas ou esquemas organizados; à medida que o indivíduo entra em contato com o mundo, ele assimila objetos e eventos a essas estruturas (assim elas funcionam e se expandem sem mudanças estruturais); quando isso não é possível porque as estruturas existentes são inadequadas, elas se modificam ou se acomodam (sofrendo alterações estruturais) ${ }^{23}$.

Em inserção ativa no mundo, o sujeito do conhecimento desenvolve estruturas de compreensão que, continuamente, no dizer piagetiano, são desequilibradas ou desafiadas. O resultado dessas interações pode gerar processos de assimilação em que os esquemas/estruturas de interpretação dão conta de incorporar a nova experiência expandindo-se - ou de acomodação quando os esquemas disponíveis não são suficientes e terminam por modificar-se para acomodar a nova experiência e as propriedades objetivamente dadas pelo novo objeto de conhecimento, alterando o esquema assimilador. O resultado é a construção de estruturas de compreensão cada vez mais equilibradas e uma estruturação de significado progressivamente mais abrangente do mundo ${ }^{24}$.

Tal processo não se confunde com o empirismo - Gruber e Vonèche ${ }^{25}$ chegam a dizer que Piaget consideraria essa interpretação um "pecado mortal". Rocha e Melo $^{26}$ definem a perspectiva associativista positivista como amparada na noção de fato e em operações relacionais para atribuição de sentido ("semelhante a", "igual a", "diferente de" etc.). Ressaltam a assimilação como um processo no qual há uma relação indissociável entre sujeito e objeto e "não uma simples relação de semelhança ou contiguidade entre os objetos conhecidos ou a serem conhecidos, como se as atividades do sujeito não interviessem no conhecimento" ${ }^{27}$. Com efeito, Piaget e Garcia $^{28}$ entendem que o fato não existe independente do observador:
18. LOURENÇO, Orlando; MACHADO, Armando. op. cit.

19. Ibidem, p. 148.

20. BARTELMEBS, Roberta Chiesa. op. cit.

21. Ibidem, p. 157-158.

22. GRUBER, Howard E. VONECHE, J. Jacques. op. cit, p. xxviii, tradução nossa.

23. No original: "At any point in its development, it may be described as a set of organized structures or schemes; as the individual encounters his world, he assimilates objects and events to these structures (thus they function and expand without structural change); when this is not possible because the existing structures are inadequate, they modify themselves or accommodate (thus they undergo structural changes)".

24. SANCHIS, Isabelle de Paiva; MAHFOUD, Miguel. Construtivismo: desdobramentos teóricos e no campo da educação. Revista Eletrônica de Educação, São Carlos, v. 4, n. 1, p. 21, 2010

25. GRUBER, Howard E. VONĖCHE, J. Jacques. op. cit, p. xxvii.

26. ROCHA, Heitor Costa Lima da; MELO, Maria Cecília Mendonça. A dimensão educativa do jornalismo construtivista: epistemologia, naturalização e mudança social. Estudos em Comunicação, Covilhã, n. 16, p. 89-110, 2014.

27. Ibidem, p. 100.

28. PIAGET, Jean; GARCIA Rolando. Psicogênese e história das ciências. Petrópolis: Vozes, 2011. 
comunicação \& educação • Ano XXVI • número 1 • jan/jun 2021

[...] um fato será sempre o produto de composição de uma parte fornecida pelos objetivos e de uma outra construída pelo sujeito. A intervenção deste último é tão importante que pode levar até a uma deformação ou mesmo recalque do observável, o que desfigura o fato em função da interpretação ${ }^{29}$.

Apesar de dependente da interação com o meio, o desenvolvimento cognitivo é um processo de autoconstrução do sujeito, posto que é governado pelas formações cognitivas previamente existentes ${ }^{30}$. Na curiosa metáfora utilizada pelos autores, os eventos ambientais são "mastigados e digeridos", gerando mudanças estruturais individuais mais ou menos fundamentais. Piaget e Garcia ${ }^{31}$ identificam três níveis de equilibração na construção de um conhecimento: intra (relativo à acomodação propriamente dita dos objetos nos esquemas de pensamento específicos), inter (incorporações recíprocas dos esquemas de pensamento ligados ao esquema recém-modificado) e trans (estabelecimento de hierarquias entre relações colaterais). Conforme se desenvolve, o indivíduo se torna mais e mais consciente de seus processos intelectuais, sendo capaz de refletir sobre eles.

\section{A CONCEPÇÃO PIAGETIANA DE EDUCAÇÃO}

Conforme Sanchis e Mahfoud ${ }^{32}$, Piaget é hoje tido como a principal referência do construtivismo, termo que designa "conjunto teórico e de práticas que abrange a obra de muitos autores e desdobramentos práticos diversificados" - definição vaga mas que evita a suposição equivocada de que o construtivismo seria a simples transposição da epistemologia genética de Piaget. Os autores também destacam que Piaget, apesar de ter dedicado uma parte de sua obra a reflexões sobre a educação escolar, não foi e não pretendeu ser pedagogo. Não legou, portanto, um "método construtivista" - os que assim se denominam seriam construções inspiradas na teoria de Piaget, principalmente as sobre o desenvolvimento infantil "e/ou em autores que desenvolveram suas pesquisas na mesma linha" ${ }^{33}$.

De todo modo, pode-se dizer que a escolarização por ele defendida deveria ter o estudante no centro, agindo e experimentando os objetos, em intercâmbio e colaboração. Em Psicologia e pedagogia ${ }^{34}$, texto que teve a primeira parte publicada em 1935 e um complemento em 1965, ao avaliar as mudanças educacionais compreendidas no intervalo de 30 anos, o autor avalia os métodos educacionais então disponíveis:

Métodos receptivos ou de transmissão pelo mestre: fortemente criticados pelo autor, que aponta um "conflito dialético" na proposta - a preparação para a vida adulta que favoreceria o ensino por transmissão, em oposição ao papel construtivo da ação que favoreceria o ensino por atividades. Piaget nota que, na década de 1960, mesmo os métodos tradicionais já buscavam uma "síntese" entre os dois polos, ainda que a "atividade" fosse representada, na maioria das vezes, por algum tipo de lição padronizada - opção também criticada por representar "a solução mais fácil” em comparação às pesquisas ativas individuais ou aos trabalhos em equipe.

Métodos ativos: Piaget sinaliza o avanço dessa perspectiva pela superação de dois "mal-entendidos" - compreendeu-se que a escola ativa não é apenas uma 


\section{Contribuições piagetianas • Rodrigo Pelegrini Ratier}

escola de trabalhos manuais e que o interesse do educando não exclui a necessidade de esforço. O primeiro ponto enfatiza que "a atividade mais autêntica de pesquisa pode manifestar-se no plano da reflexão, da abstração mais avançada e de manipulações verbais" ${ }^{35}$; o segundo, que o individualismo anárquico não tem espaço na escola ativa. Em seu lugar, deve florescer uma combinação de trabalho individual e do trabalho por equipes, favorecendo a educação da autodisciplina e do esforço voluntário. Apesar dos avanços, Piaget pontua a relativa ausência de progressos nas práticas ativas. A principal razão seria a dificuldade de aplicação da metodologia, que exigiria uma formação docente muito mais sofisticada. Por ser relevante, transcrevemos uma longa citação:

Os métodos ativos são muito mais difíceis de serem empregados do que os métodos receptivos correntes. Por um lado, exigem do mestre um trabalho bem mais diferenciado e bem mais ativo, enquanto dar lições é menos fatigante e corresponde a uma tendência muito mais natural no adulto em geral e no adulto pedagogo em particular. Por outro lado, principalmente, uma pedagogia ativa implica uma formação muito mais consequente, e sem conhecimento suficiente da psicologia da criança (e, para os ramos matemáticos e físicos, sem um conhecimento bastante forte das tendências contemporâneas destas disciplinas), o mestre compreende mal as condutas espontâneas dos educandos e não chega a aproveitar-se do que considera insignificante e simples perda de tempo. O drama da pedagogia, como, aliás, o da medicina e de outros ramos mais que compartilham, ao mesmo tempo, da arte e da ciência, é, de fato, o de que os melhores métodos são os mais difíceis: não se pode utilizar um método socrático sem ter adquirido, previamente, algumas das qualidades de Sócrates, a começar por certo respeito à inteligência em formação ${ }^{36}$.

Métodos intuitivos: tidos pelo autor como uma das causas do atraso dos métodos ativos, são empregados de boa-fé por educadores que reduzem a noção de atividade à ação concreta ou a simulações do objeto do conhecimento. Piaget ressalta que esse tipo de escolha não contempla os níveis superiores de desenvolvimento intelectual (o pensamento operatório, típico dos adultos), quando a atividade deve incidir "sobre a reflexão interior e abstrata".

Métodos programados e máquinas de aprender: comentando sobre as "máquinas de ensinar" ${ }^{37}$ então propostas por Skinner - uma espécie de protoeducação a distância -, Piaget afirma que o aparente êxito das máquinas em substituição aos professores mostra, "sem réplica", o caráter mecânico da função do mestre no ensino tradicional. Se o ensino visa apenas a repetição do que foi exposto, um autômato pode realizá-lo. No entanto, o autor concede que a adoção de máquinas pode dar lugar a um equilíbrio entre as "partes de registro" e a "atividade livre": as máquinas poderiam abreviar o tempo gasto com o ensino tradicional e liberar espaço para o trabalho ativo.

\section{CONTRIBUIÇÕES PARA A SALA DE AULA}

Este belo volume, preparado por Howard E. Gruber e Jacques Vonèche, me parece a melhor e a mais completa de todas as antologias do meu trabalho. É, além disso, um modelo [de antologia], porque em vez de se limitarem a justapor trechos de 


\section{comunicação \& educação • Ano XXVI • número 1 • jan/jun 2021}

38. PIAGET, Jean. Foreword. In: GRUBER, Howard E.; VONĖCHE, J. Jacques. The essential Piaget. London: Routledge: Kegan Paul, 1977. p. xi, tradução nossa.

39. No original: "This fine volume, prepared by Howard E. Gruber and Jacques Vonèche, seems to me the best and the most com plete of all anthologies of my work. It is, in addition, a model of its kind, because instead of limiting themselves to juxtaposing extracts of books or articles, [(...]), the collaborators have accompanied each selection with a very intelligent commentary that illuminates the general movement of thought as well as the particular meaning of a given selection. I could say that, in reading the explanatory texts, I came to understand better what I had wanted to do [...]".

40. PIAGET, Jean, op. cit, 1977, p. xi.

41. MACEDO, Lino. A perspectiva de Jean Piaget. São Paulo: FDE, 1994.

42. MACEDO, Lino de. Los sujetos de Piaget y su educación. In: MADRUGA GARCÍA, Juan Antonio. Construyendo mentes. Ensaios en homenaje a Juan Delval. Madrid: Universidad Nacional de Educación a Distância, 2012. p. 281.

43. Ibidem, p. 282. Tradução do autor: "Planejar, propor, observar, acompanhar, avaliar, desencadear problemas e respeitar os processos de desenvolvimento e aprendizado do sujeito epistêmico em todos os seus modos de expressão". livros ou artigos, [...], os colaboradores acompanham cada seleção com um comentário muito inteligente que ilumina tanto o movimento geral do pensamento como o significado particular de uma determinada seleção. Eu poderia dizer que, ao ler os textos explicativos, entendi melhor o que eu quis fazer $[\ldots]^{38,39}$.

É assim que Piaget referenda o trabalho de dois discípulos, Gruber e Vonèche, no prefácio de The essential Piaget, uma coletânea comentada de seus principais trabalhos. O suíço demonstra gratidão à dupla de editores por não terem reduzido seu trabalho à psicologia da criança. Ao contrário, conseguem captar, segundo ele, que seu objetivo principal sempre foi entender o que ele define como "interpretação epistemológica" $"$.

Para o escopo da presente discussão, é de particular interesse a introdução dos autores aos textos selecionados sobre educação. Nela, Gruber e Vonèche fazem coro à rejeição da existência de dogmas piagetianos sobre educação, o que não significa que sua epistemologia genética não possa inspirar o ambiente do ensino e da aprendizagem. Conforme Macedo ${ }^{41}$, cabe ao professor derivar da teoria piagetiana sua prática. No caso de Gruber e Vonèche, em vez de enumerar uma lista de aplicações contemporâneas, a opção é oferecer uma esquematização de abordagens possíveis. Em um artigo que revisa tal proposta, Lino de Macedo, tido como um dos principais especialistas em Piaget no Brasil, considera que a proposição de Gruber e Vonèche sintetiza bem um modo interacionista e construtivista de educar os sujeitos de Piaget. Enfatiza, ainda, que se trata de modos de atuação e não preceitos a serem seguidos, podendo ser considerados no ensino de muitos conteúdos ${ }^{42}$.

Para nomear tais modos de atuação, Gruber e Vonèche usam metáforas de cidades ou figuras da sabedoria universal. Na diferenciação entre elas, levam em conta dois aspectos principais: o uso de materiais e/ou exercícios e o tipo de relação social considerada. As abordagens sugeridas são as seguintes:

Tao: ao recorrer ao símbolo chinês para caminho, os autores iluminam o papel do professor enquanto "artesão individual”, que deve saber propor materiais (físicos ou não) apropriados para os processos de desenvolvimento dos educandos. É o docente que cria desafios adequados às características individuais e socioculturais dos educandos, favorecendo a atividade mental e a passagem de um nível de conhecimento a outro superior. Suas tarefas incluem "planear, proponer, observar, acompañar, evaluar, desencadenar problemas y respetar los procesos de desarrollo y aprendizaje del sujeto epistémico en todas sus modalidades de expresión”³.

Paris: a cidade dos encontros e da socialização nomeia a discussão, o diálogo e a interação entre iguais, mediados ou coordenados por um profissional competente. Segundo Macedo, com um par, o educando pode aprender a refletir por que o(a) parceiro(a) exige checagens, argumentos, e discute ou apresenta outros aspectos relacionados ao problema em disputa. Ao professor cabe o papel essencial na regulação do debate, formulação de questões e eventual implementação de hipóteses decididas coletivamente.

Atenas: o recurso da cidade grega, berço da democracia, remete ao método socrático. A ênfase, aqui, é no papel do educador. À moda de Sócrates, é ele quem faz perguntas, propõe problemas e fornece materiais quando necessário. Entre as 
hipóteses levantadas pelos educandos, valoriza os caminhos mais férteis para a evolução do raciocínio. Macedo afirma que essa abordagem exige do docente conhecimento sobre o desenvolvimento do pensamento e, da escola, a criação de um ambiente de segurança onde se pode dizer o que acredita sem medo de estar errado ${ }^{44}$.

Eldorado: o lugar mítico de extraordinária riqueza escondido na selva designa o professor que se abre para participar nos processos de descoberta e aprendizagem do educando. Pensar junto sobre um problema, compartilhar a busca de soluções coletivas, considerar com genuíno interesse as ideias e hipóteses sobre uma questão, valorizar os diálogos, interações e reflexões são de imensa valia para todos.

O "tesouro", para os educandos, é a possibilidade de ensinar. Para os professores, a de continuar aprendendo ${ }^{45}$.

\section{APONTAMENTOS PARA O ENSINO DE JORNALISMO}

A perspectiva construtivista inspirada em Piaget sugere um reexame global das metodologias, rotinas e práticas empregadas nos cursos de Jornalismo, do planejamento à avaliação. Se é verdade que a teoria piagetiana tem tido o grosso de suas adaptações práticas no contexto da escolarização básica, seus preceitos podem inspirar transformações no Ensino Superior. Não se pretende com isso desconsiderar as especificidades dessa etapa de ensino, tampouco a complexidade de seus objetos do conhecimento A intenção, aqui, é apresentar algumas notas para a renovação da prática docente, que podem tomar a forma de adaptações incrementais a profundas transformações metodológicas.

Como afirmamos, são raros os registros de experiência referenciados em bibliografia clássica do campo da educação. É razoável esperar, portanto, que as práticas nas salas de aula estejam muito próximas do ensino tradicional - o da aula magistral, expositiva, que exige do professor o domínio do conteúdo que ministra e "nada mais". Um primeiro aspecto a se considerar é a necessidade de propor, cotidianamente, atividades que mobilizem o pensamento dos educandos. É preciso planejar e apresentar problemas que interessem ao alunado e representem um desafio real e possível de ser superado nos limites do que Vigotsky ${ }^{46}$ chama de "zona de desenvolvimento proximal" - o nível que um educando consegue atingir, com uma pequena assistência do educador (uma pergunta importante que encaminhe à solução, o passo inicial da investigação), ao resolver um desafio mais difícil do que ele seria capaz sozinho. Para dizer o mesmo com terminologia piagetiana: considerar a necessidade de estruturar situações didáticas voltadas para o desequilíbrio/reequilíbrio das estruturas cognitivas existentes.

O curso de Jornalismo apresenta oportunidades férteis para esse avanço, sendo o eixo laboratorial ${ }^{47} \mathrm{o}$ mais evidente. Dessa perspectiva, contudo, faz-se necessária vigilância para que a "mão na massa" não se transforme em prática espontaneísta com orientação docente insuficiente, ausente ou de caráter meramente celebratório dos conhecimentos precedentes dos educandos. A armadilha a evitar é o empirismo puro e simples, com educandos fazendo escolhas com base em tentativa e

44. Ibidem, p. 285. 45. Ibidem, p. 286. 46. VIGOTSKY, Lev S. Pensamento e linguagem. São Paulo: Martins Fontes, 2008. 47. BRASIL, op. cit. 
erro, como muitas vezes ocorre no ambiente de trabalho. Macedo ${ }^{48}$ alerta, ainda, para que se evite o oposto, ou seja, o professor que usa de sua autoridade para dar lições e antecipar respostas.

Uma crítica recorrente às metodologias ditas construtivistas se refere a um suposto "apagamento" do docente. O raciocínio é que, se o foco está no educando e, mais especificamente, em sua ação para a construção do conhecimento, o educador se tornaria uma figura dispensável. O próprio Piaget se encarrega de desaconselhar tal interpretação, reservando ao educador o papel de orientador do processo de aprendizagem - tarefa ainda mais complexa que a de um professor dito "tradicional"; posto que, aos saberes específicos de sua área de ensino, passa a ser necessário compreender como se desenvolve o conhecimento, incentivando o conflito cognitivo, sabendo lidar com o erro e planejando/organizando atividades/ processos/interações mais adequados para essa construção:

Mas é evidente que o educador continua indispensável, a título de animador, para criar situações e armar os dispositivos iniciais capazes de suscitar problemas úteis para a criança, e para organizar, em seguida, contra-exemplos que levem à reflexão e obriguem ao controle das soluções demasiado apressadas: o que se deseja é que o professor deixe de ser apenas um conferencista e que estimule a pesquisa e o esforço, ao invés de se contentar com a transmissão de soluções já prontas ${ }^{49}$.

Adicionalmente, é possível repensar situações de debate sem motivação clara e/ou sem direcionamento suficiente, fazendo com que a interação derive para conversas banais ou orientadas pelo senso comum. O desenvolvimento da dimensão coletiva do sujeito epistêmico envolve um trabalho baseado em autodisciplina e esforço para a compreensão. Nesse sentido, tanto o modelo docente como exemplo de investigador de hipóteses quanto seu papel na orientação de caminhos para possíveis soluções são imprescindíveis.

Uma última consideração abarca os enormes desafios que a revisão de metodologias de ensino representa para a formação dos professores do campo do jornalismo e da comunicação. Estes não costumam contar com disciplinas e/ou atividades de preparação didático-pedagógicas ao longo de suas trajetórias na graduação e na pós-graduação. Sem um referencial reflexivo consistente, muitos acabam ensinando como aprenderam, reproduzindo práticas espontaneístas e a concepção tradicional do ensino - transmissiva -, que da perspectiva piagetiana pouco impacta o desenvolvimento do conhecimento.

48. MACEDO, Lino de. op. cit, 1994.

49. PIAGET, Jean. Para onde vai a educação? n. ed. Rio de Janeiro: José Olympio, 1988, p. 18.

\section{CONSIDERAÇÕES FINAIS}

Ao longo deste artigo, procuramos trazer apontamentos de como a interlocução com as concepções de construção de conhecimento e de educação de Jean Piaget podem colaborar para uma renovação do ensino de jornalismo, convidando à reflexão sobre práticas arraigadas e reproduzidas de forma quase automática, geração após geração, pela relativa ausência de referências educacionais para a estruturação de uma metodologia pedagógica própria. Num contexto 
mais específico e ambicioso, pode-se falar em Piaget como inspiração para a construção de uma didática específica do jornalismo, correlata à sua especificidade como campo de pesquisa e de formação. A escolarização básica já apresenta vasta trajetória de apropriação da inspiração construtivista em terrenos, como alfabetização (a exemplo dos trabalhos de Emilia Ferreiro e Ana Teberosky), matemática (Constance Kamii) e desenvolvimento moral (Lawrence Kohlberg).

A indissociável natureza teórico-prática da profissão apresenta possibilidades de desenvolvimento de uma pedagogia interacionista baseada na ação do educando que constrói seu conhecimento. Trabalho esse que, conforme nos lembram Gruber e Vonèche $^{50}$, não possui fórmula pronta, exigindo capacidade criativa ("A observação de Piaget, de que apenas reinventando uma teoria as crianças podem entendê-la, é igualmente válida para todos os adultos. Se o professor quiser entender o que está fazendo, ele deve inventar" ${ }^{51}$ ). Ao contrário: encontra-se à espera de docentes que sejam capazes de reinventar sua prática com o rigor pedagógico que ela exige.

\section{REFERÊNCIAS BIBLIOGRÁFICAS}

ABRAMO, Perseu. Jornalismo: profissão específica ou atividade geral? Folha de S.Paulo, São Paulo, 2 out. 1987. Disponível em: https:/ /www.lainsignia.org/ 2001/junio/cul_054.htm. Acesso em: 1 ago. 2020.

BARTELMEBS, Roberta Chiesa. Psicogênese e história das ciências: elementos para uma epistemologia construtivista. Revista Ensaio, Belo Horizonte, v. 16, n. 2, p. 147-165, 2014.

BRASIL. Ministério da Educação. Conselho Nacional de Educação. Resolução $\mathrm{n}^{\mathrm{o}} 1$, de 27 de setembro de 2013. Institui as Diretrizes Curriculares Nacionais para o curso de graduação em Jornalismo, bacharelado, e dá outras providências. Diário Oficial da União: seção 1, Brasília, DF, p. 26, 27 set. 2013. Disponível em: http://portal.mec.gov.br/index.php?option=com_ docman\&view=download\&alias=14242-rces001-13\&category_slug=setembro2013-pdf\&.Itemid=30192. Acesso em: 1 ago. 2020.

GADOTTI, Moacir. História das ideias pedagógicas. 4. ed. São Paulo: Ática, 1996.

GRUBER, Howard E.; VONÈCHE, J. Jacques. The essential Piaget. London: Routledge: Kegan Paul, 1977.

LOURENÇO, Orlando; MACHADO, Armando. In defense of Piaget's theory: a reply to 10 common criticisms. Psychological Review, [s. l. ], v. 103, n. 1, p. 143-164, 1996.

MACEDO, Lino de. Los sujetos de Piaget y su educación. In: MADRUGA GARCÍA, Juan Antonio. Construyendo mentes. Ensaios en homenaje a Juan Delval. Madrid: Universidad Nacional de Educación a Distância, 2012. p. 275-290.

MACEDO, Lino. A perspectiva de Jean Piaget. São Paulo: FDE, 1994.

50. GRUBER, Howard E. VONĖCHE, J. Jacques. op. cit, p. 694.

51. No original: "Piaget's remark, that only by reinventing a theory can the children understand it, apllies equally well to all adults. If the teacher is to understand what he is doing, he must invent it". 
MEDITSCH, Eduardo. Novas e velhas tendências: os dilemas do ensino de jornalismo na sociedade da informação. Revista Brasileira de Ensino de Jornalismo, Brasília, DF, v. 1, n. 1, p. 179-201, 2007.

PIAGET, Jean. Foreword. In: GRUBER, Howard E.; VONÈCHE, J. Jacques. The essential Piaget. London: Routledge: Kegan Paul, 1977. p. xi-xii.

PIAGET, Jean. Psicologia e pedagogia. Rio de Janeiro: Forense Universitária, 1985.

PIAGET, Jean. Para onde vai a educação? 10. ed. Rio de Janeiro: José Olympio, 1988.

PIAGET, Jean. Epistemologia genética. São Paulo: Martins Fontes, 2002.

PIAGET, Jean; GARCIA, Rolando. Psicogênese e história das ciências. Petrópolis: Vozes, 2011.

ROCHA, Heitor Costa Lima da; MELO, Maria Cecília Mendonça. A dimensão educativa do jornalismo construtivista: epistemologia, naturalização e mudança social. Estudos em Comunicação, Covilhã, n. 16, p. 89-110, 2014.

SANCHIS, Isabelle de Paiva; MAHFOUD, Miguel. Construtivismo: desdobramentos teóricos e no campo da educação. Revista Eletrônica de Educação, São Carlos, v. 4, n. 1, p. 18-33, 2010.

VIGOTSKY, Lev S. Pensamento e linguagem. São Paulo: Martins Fontes, 2008. 